\title{
Reasons of Apathy to Pandemic Instructions: Scenario in Bangladesh
}

\author{
Md. Easin Ahmed \\ Khulna University, Bangladesh
}

\begin{abstract}
Covid-19 has caused much suffering to the world. No nation could get an exemption from this contagion. To reduce impairments, people had to follow instructions given by doctors, health organizations, and governments. This research affirmed massive amount of people had always been apathetic to the given pandemic instructions and their health. This paper's purpose is to let disaffiliates know why many people are neglecting their life risk within this pandemic. It also may help to take some essential steps to reduce infection and death cases. Applying a total of 10 focus group discussions in May and June of 2020 to almost 80 random participants from roadsides and tea stalls, this paper upholds some basic narratives that demonstrate the scenario of the pandemic in Khulna, Bangladesh. Lacking proper knowledge, Frustration, Financial condition, Communication barriers, and many more reasons are liable for this kind of behavior. The media also played a very significant role. All these suggest that there are some obvious reasons for them to disregard the given instructions.
\end{abstract}

Keywords: Covid-19, Pandemic, Disobey, Apathy, Reasons, Instructions, Role of media

\section{INTRODUCTION}

A s a volunteer, in between very tough pandemic situations, I had to go out regularly. From the beginning of covid-19 to till now, I have never experienced a single day where $100 \%$ of people obeyed preventing instructions. Even I got influenced in some cases by not wearing hand gloves and PPE. So, I started to discern them, talk to them, and realizing their solicitudes.

It has been noted (Dey et al, 2020) that Bangladesh has familiarized its very first laboratory tested confirmed Covid19 patients on 8 March 2020, and it reported its first death case on 18 March 2020. Official update page corona.gov.bd of Bangladesh exhibited Covid-19 has caused 8,127 deaths and 535,139 corona cases within 3651,722 tests in Bangladesh within its ten months of epidemic. Familiar with nature, environment, and geography, neighboring countries like Srilanka, Myanmar, Bhutan have a better situation than Bangladesh. Srilanka has 316 deaths and 64,157 infected till January 2021. Myanmar has 140,145 cases and 3,131 deaths, and Bhutan has 859 cases with just a single death report (worldometer, 2020).

Bangladesh stopped the interior flight on 24th March and bus traveling on 26th March of 2020. On 26th March, the shutdown was announced by the Government. Wearing musk was a must, the gathering was highly banned, and going out or going into lockdown areas was highly prohibited.
Nevertheless, the majority of Bangladesh never sustained any instructions given by doctors, health organizations, and the Government. The present scenario of every district is as if the coronavirus does not exist in Bangladesh.

Saleh (2020) argued, "In Bangladesh where 90\% of workers are in the informal sector, health insurance is a luxury, and maximum homes do not have any sort of internet connectivity." World Bank data (as cited by Saleh, 2020) revealed that Bangladesh has eight hospital beds for every 10,000 people. It has been stated (worldometer, 2020) that Bangladesh is testing 3,642 people per $10 \mathrm{lakh}$, which is 2nd in the undermost list of testing within the countries which have more than a lakh infected people.

Knowing the shortage of health facilities and the gruesomeness of coronavirus, finding out how and why people could show apathy to the pandemic instructions was the main focus of this study.

\section{METHODOLOGY AND ANALYSIS}

Focus group discussions were used as a qualitative research approach to achieve an in-depth understanding of people's attitudes toward pandemic instructions apathy.

Respondents were selected randomly from those who were neglecting preventing instructions in Khulna city of Bangladesh. People from roadsides and isolated tea stalls were mainly targeted as sources of data because of having easy access to several people within the pandemic situation. Samples were mixed by ages, education, and professions.

To take participants' opinions, I used to enter in a group of people then started approaching them to be respondents saying, there are some instructions to get rid of this contagion, but we are not being able to follow those. To find out why through research, I am inviting you all to a focus group discussion; those who are interested, please cooperate. Not surprisingly, there were a vast number of refusals to take part. In this case, I always ensured a minimum of seven to eight participants to all 10 focus group discussions, which all were held in May and June of 2020. Within and after discussion, necessary notes were taken consciously.

\section{FINDINGS AND DISCUSSION}

\section{Knowledge Gap}

The majority of Bangladesh had inaccurate knowledge on covid-19. They believed that if someone touches someone 
infected only, they could get infected too; otherwise, they will not. By this, they never followed necessary instructions except having distance from suspects.

People also believed that covid-19 is a grave disease. This misinformation influenced people to misbehave with the covid-19 infected and also with the symptoms bearers. As a result, people got apathy to test covid-19 even having symptoms and at the same time used to manage daily life with surroundings.

\section{Myth and Misconception}

People from different areas had a rumor that corona is a disease for the rich; nothing will happen with the poor. There was also a saying that Chinese people eat bats; that is why they got infected and Bangladesh's rich people are infected by their presence with them. Consequently, this is the initial understanding of Bangladeshi peoples. Though people got to know it is a disease for all, there were many misbeliefs within them. As like, peoples of Barishal and almost all over the country started having 'Centella Asiatica as a medical herb because of spreading rumors as it has a cure. Rather than getting doctors' concerns, people did what they got to know.

There were a vast number of people who had a common thought that corona can never injure them. As in that thought, they never conducted any instructions. Some people were so stubborn that, in between the Army and law enforcement interferences, people never maintained lockdown. Almighty has given the disease so he will take care of it; why should we stop our daily life! It was a firm thought which was established among communities.

Ultimately misconceptions and several rumors created apathy to disobey the instructions.

\section{Frustration}

An abrupt change of daily habits affected human lives quite harshly. Naturally, everyone cannot remain mentally strong. All could not take this pandemic and lockdown situation. Moreover, frustration and suicidal news often go viral on every media. Many got frustrated. To avoid frustration, especially the young generation used to disobey the instructions like not being at home, not maintaining social distance, going out and many more.

Gradually fear of frustration and suicidal cases influenced people to violate rules. People aspired to make them comfortable. So, instead of being frustrated by obeying instructions, a considerable amount of people preferred to disobey. They found death by diseases more competent than being in frustration or committing suicide.

\section{High Density of Population}

The population has always been an obstacle for this country. The population density in Bangladesh is 1265 per $\mathrm{Km} 2$. Furthermore, Bangladesh ranks number eight in the list of countries (and dependencies) by population (worldometer,
2021). It can be stated that, except for the wealthy families, several people of a family have to use the same latrine. Especially people who live in slums must meet people while using latrine or water sources. Even families of numerous members have to share a single bedroom. So, the situation is not helping them to be conscious of given instructions. Eventually, they were bound to violate given instructions.

\section{Financial Condition}

The financial condition of most of the peoples of Bangladesh is not so subsidiary. Most of the people here have to live from hand to mouth. Though Government and private organizations provided succor, it was not enough for them.

Subsequently, people had to go out to earn, and intending to reduce their cost was quite usual. Where people's had to face troubles to get a livelihood, expending money to buy sanitizers, soaps, masks, and other necessary resistants were a luxury to them.

\section{Weather}

Though Bangladesh is a temperate country, the ratio of summer months is maximum here. In recent years the summertime temperatures have risen on average 35-40 degrees Celsius. People have to strive with heat and sweat. Within this situation, using unhabitual things like masks, gloves, or anything else became a hardship. So, this made them compelling to not wear masks or any preventive shields.

\section{Gossipy}

It was perceived that the common nature of the Bangladeshi majority is gossipy. People, especially the less educated, love to share their own, others, societal, and overseas stories. Being locked in a room alone for an extended period was almost impossible for them. That was why in between the lockdown, people were always found in the tea stalls and roads.

\section{Communication Barriers}

Concentrating on the face, lips, or eyes is typical human behavior. But using masks settled barriers to conversations. Also, using masks, unfortunately, makes speech unclear, lower toned, and confusing. Using masks has one more issue; eyeglasses become dim when eyeglass users wear masks. Consequently, clearing the $\operatorname{dim}$ condition forms a communication barrier and unwillingness to talk.

Not only masks but also the other resistants like face shield, PPE, etc., create troubles while communicating.

\section{Habitual Change}

The covid-19 epidemic brought a lot of unwanted troubles. People got irritated with all the troubles that were introduced by corona. The unwanted troubles are wearing masks, eyeglasses, face-shield, PPE, using sanitizer, washing hands regularly, obeying lockdown, maintaining distance from others, and many more. These became unbearable to the 
peace-loving peoples and obeyed almost all the resistant instructions given to be safe from the corona.

\section{Role Played by Media}

The media had the power to retain people's attention to the needed instructions. After some months of the pandemic, people did not even take a look at the number of infections per day. Now 'does corona exist!' has become a common thought. The media should get enough of the liabilities of apathy to know the infection rate by giving much importance to it. People got bored with the infection rate by the eventual (every moment's update) publication and broadcast.

Observation indicates, the media gave its major concern on the infection rate of the higher infected countries like the USA, Italy, and China. Nevertheless, the media never gave much attention to countries with familiarities with Bangladesh by geography, population, weather, and neighboring countries like Srilanka, Myanmar, Bhutan, and others.

Besides, the media used to publish news mostly based on peoples not obeying instructions and lockdown situations. Watching this type of news, the majority got influenced that others are not obeying then why we. But the media could focus on the destructive effects equally, or more of not maintaining the necessary instructions to the people might not be distracted.

\section{CONCLUSION}

Covid-19 has caused more suffering to this planet than any other virus in history. For more than a year, this contagion has ruled the populace, and no one knows when it will stop. On the one side, disaffiliates are battling to contain the virus's spread. On the other side, people disregard all instructions. This finding confers some confidence that it has some obvious reasons but people should not refuse to comply must need instructions. As the welfare of own and others rely on each person, all must maintain discipline despite apparent apathy.

\section{REFERENCES}

[1] Dey, S.K., Rahman, M., Siddiqi, U.R. et al. Exploring Epidemiological Behavior of Novel Coronavirus (COVID-19) Outbreak in Bangladesh. SN Compr. Clin. Med. 2, 1724-1732 (2020). https://doi.org/10.1007/s42399-020-00477-9

[2] Saleh, A. (2020), In Bangladesh, COVID-19 threatens to cause a humanitarian crisis, $<$ https://www.weforum.org/agenda/2020/04/in-bangladesh-covid19-could-cause-a-humanitariancrisis/?fbclid=IwAR1jmX4gpYIQrJLEkBSUHd4ThcIO7eceRi2Cp cCn7rfGfRzVgY0nx9aClQY>

[3] Worldometer. (2020) Covid-19 Coronavirus Pandemic. Available at: www.worldometers.info/coronavirus/

[4] Worldometer. (2021) Bangladesh Population 2021. Available at: https://www.worldometers.info/world-population/bangladeshpopulation/ 